\title{
Dell Hymes
}

\section{Pidginization and Creolization of Languages: Their Social Contexts}

https://doi.org/10.1515/ijsl-2020-2088

\begin{abstract}
Sociolinguistic debates around the definitions and significance of "pidgin" and “creole" languages were increasing in the 1960s and the SSRC's Committee on Sociolinguistics played a role in cultivating these discussions. This 1968 report by Dell Hymes summarizes issues raised at a conference convened by the Council at the University of the West Indies, Jamaica, to better understand the historical development, the grammatical and lexical evolutions, and the social uses of pidgin and creole languages. Though he highlights how social science can better inform research on pidginization and creolization, Hymes identifies knowledge gaps, among them the nature of the relationship between these languages and national identity, and more broadly the lack of historical and social scientific knowledge of this topic.
\end{abstract}

Languages called "pidgins" and "creoles" have been something of a stepchild in scientific research, but their origins and social functions pose in particularly clear form problems of the sort with which the Council's Committee on Sociolinguistics is concerned. In analyzing historical change and in describing present structure in language, linguists often find it possible to take social factors for granted. Work proceeds as if something that might be called "normal transmission" of speech from one generation to the next could be assumed, or as if the sample of speech provided by one's informants could be safely assumed to represent a norm identical throughout the community. Whether these assumptions are justified is open to question; what is clear is that even the ordinary work of the linguist cannot proceed without questioning them in the case of "pidgins" and "creoles." These languages demonstrate dramatically the interdependence of linguistics and social science, and open up new possibilities for the integration of their methods and theories. During the past decade there has been a notable growth of interest and information concerning such languages, whose implications have not yet been widely recognized.

For these reasons an international conference was organized to encourage research on situations of pidginization and creolization, and call attention to its

Dell Hymes, University of Pennsylvania, USA

Ә Open Access. () 2020 Hymes, published by De Gruyter. (c) BY Creative Commons Attribution 4.0 Public License. 
importance. The conference was cosponsored by the committee and the University of the West Indies, which has been the principal site of the development of creole studies in the past decade, and was held at the campus of the University in Mona, Jamaica, on April 9-12, 1968. By meeting in Jamaica, the conference was able to benefit from the participation of a number of Caribbean scholars for whom creolized languages are of personal and practical, as well as theoretical, importance. The depth and realism of some of the discussion reflected their presence.

Most of the participants in the conference were linguists, but many of them had some social science training and about one of four was affiliated with a social science department. ${ }^{1}$ The papers prepared for the conference were grouped for discussion according to several main topics of concern: general conceptions of the nature of pidginization and creolization; analysis of specific characteristics and processes; reconstruction of the origins and history of such languages; recognition of the past occurrence of creolization in the history of a language; analysis of contemporary pidginization and creolization; and studies of the social role of pidgin and creole languages in contemporary communities. Two social scientists and two linguists were given the special task of reviewing

1 In addition to Charles A. Ferguson, Allen D. Grimshaw, Dell Hymes, William D. Labov, and Elbridge Sibley of the Committee on Sociolinguistics, the 85 participants included 4 members of the University of the West Indies staff-Mervyn Alleyne, Gertrud Buscher, Dennis R. Craig, John Figueroa; and the following: Beryl Bailey, Yeshiva University; Jack Berry, Morris Goodman, Northwestern University; Frederic G. Cassidy, University of Wisconsin, Madison; David DeCamp, Edgar G. Polomé, University of Texas; Joseph Dillard, Université Officielle de Bujumbura; Christian Eersel, Taalbureau, Surinam; Charles O. Frake, Stanford University; Henry M. Hoenigswald, University of Pennsylvania; Terence Kaufman, University of California, Berkeley; David Lawton, Inter-American University, Puerto Rico; Robert B. Le Page, University of York; Sidney W. Mintz, Yale University; John Reinecke, Honolulu; Karl Reisman, Brandeis University; Irvine Richardson, Michigan State University; William J. Samarin, Hartford Seminary Foundation; Franklin Southworth, Columbia University; William A. Stewart, Center for Applied Linguistics; Douglas Taylor, Paramaribo, Surinam; Stanley M. Tsuzaki, University of Hawaii; Albert Valdman, Indiana University; Jan Voorhoeve, University of Leiden; Keith Whinnom, University of Exeter. The conference was also attended by Richard Allsopp, Lawrence Carrington, Jean D'Costa, Kemlin Laurence, Joan McLaughlin, Donald Wilson, University of the West Indies; D. Bickerton, A. C. Nunn, University of Guyana; Elizabeth Carr, University of Hawaii; and Martin Joos, University of Toronto, as observers. Jan Daeleman, S. I., Louvanium University, Congo; John Gumperz, University of California, Berkeley; and Ian Hancock, London, contributed material to the conference but were unable to attend. The author is especially indebted to David DeCamp, whose survey of the field of creole studies, circulated to the participants, contributed to the background of this report. 
the conference at its last session: Sidney Mintz (an anthropologist specializing in Caribbean cultures) from the standpoint of social history; Henry Hoenigswald from the standpoint of a specialist in comparative and historical linguistics; Allen Grimshaw as a member of the Council's Committee on Comparative Sociological Research; and William Labov from the standpoint of an innovator in sociolinguistic analysis.

\section{"Pidgin" and "creole": Background}

The conference sought to focus attention on processes, and to avoid popular connotations of the terms "pidgin" and "creole." The terms have clear and standard scientific meanings. A pidgin is defined as a stable form of speech that is not learned as a first language (mother tongue) by any of its users, but as an auxiliary language by all; whose functions are sharply restricted (e.g., to trade, supervision of work, administration, communication with visitors), and whose vocabulary and overt structure are sharply reduced, in comparison with those of the languages from which they are derived. A creole is defined as an ordinary language that is derived from a pidgin and that through one or another set of circumstances has become the first language of a community, has been adapted to the full range of functions of community life, and has become notably richer in lexicon and structure than the pidgin from which it arose.

In most circumstances in which creoles are found they are considered socially inferior, even though sometimes thought superior in expressiveness. In ordinary usage the term pidgin suggests a mishmash, and certainly inferiority; only rarely, as among some peoples of New Guinea, is knowledge of a pidgin a badge of cosmopolitanism and male superiority. At best these languages are considered marginal; at worst, debased forms of speech without structure or value. Such attitudes have made them seem unworthy of study to most of their users and to those concerned with them officially, and have perhaps contributed to the relative absence of their study by others.

The common etymology for pidgin reflects these views. It is thought to be an Asian corruption of English "business," although the changes in pronunciation are unparalleled and unlikely. In fact, the word is a sixteenth-century English "corruption" of a South American Indian term (Pidian) applied to the people with whom one traded and hence to the language used in trade (cf. Indian: Injun). The term and form of speech were carried over the world in the early years of European expansion and colonization. Indeed, one major theory is that almost all the world's pidgins and creoles have their origin in an Afro-Portuguese pidgin 
developed on the coasts of West Africa, itself perhaps adapted from a Portuguese version of the medieval Mediterranean pidgin, Sabir, and subsequently rapidly replenished in vocabulary ("relexified") from Spanish, English, Dutch, or French, as the case might be, in various parts of the Caribbean, the Pacific, and Asia.

Though restricted in content and use, pidgins are real languages with structures of their own that their users must learn. Pidgin English is not just any distortion of English that comes to mind, but a specific code, indeed a series of specific codes, not mutually intelligible with standard English or necessarily with each other, as between the various sectors of Asia, the Pacific, and Africa in which they are found. There is a fair amount of literature in some pidgins, through translation and local composition.

There are probably several million persons in the world who daily use some pidginized language. Languages characterized as creoles are spoken by more than six million persons in and around the Caribbean, by a variety of groups in West Africa (Sierra Leone, Camerouns, Ivory Coast, Guinea especially), and in Asia (India, Macao, the Philippines), as well as in South Africa and Indonesia, if the creole characteristics of Afrikaans and Bahasa Indonesia are taken into account. The major contemporary cases in the United States, recognized as such, are Gullah, once spoken widely in Georgia, South Carolina, and the Sea Islands, and Hawaiian pidgin and creole.

The circumstances that give rise to such forms of speech continue to occur: in Central Africa a pidginized Sango is spreading, while the ordinary Sango from which it derives (with the aid of French) may be dying out, according to William Samarin; in Katanga a pidginized form of Swahili is reported by Edgar Polomé to be undergoing creolization. The Pidgin English (Neo-Melanesian) of New Guinea is spreading as an integrative force among speakers of New Guinea's many diverse languages, and may become the national language of the new country; an incipiently creolized Swahili has been adopted as the national language of administration and education in Tanzania.

Creoles, of whose status as full languages there is no question, are major factors in literature and education in the Caribbean and increasingly in England, and some contend that the perspective of the student of creole languages sheds light on the nature of some forms of English in use among Negroes in the United States (a point ably argued by Joseph Dillard). In short, education, administration, and sometimes quest for national identity are bound up with such languages in several parts of the world. 


\section{Simplification}

In recent years linguists have tended to avoid questions of differences in complexity and adequacy among languages. With pidgins the questions are inherent in the subject. Much of the discussion at the first session of the conference revolved around the notions of "simplification" or "reduction." Samarin treated pidginization as any "consistent reduction of the functions of language both in its grammar and its use." So regarded, pidginization is part of a wide range of phenomena, including what the British sociologist Basil Bernstein has called "restricted codes"; much of the interest in the subject lies in this relationship. From this point of view, one undertakes a general study of simplifications and reductions of speech in adaptation to others. The social context is patently crucial, since simplification attributable to lack of shared understanding must be distinguished from simplification which represents the economy of means possible to those whose shared understandings are great. Keith Whinnom emphasized, in contrast to Samarin, the rarity with which simplification and mixture of speech have led to establishment of a pidgin. He compared cocoliche, a highly unstable and variable variety of speech found among Italian immigrants in Argentina, with Chinese Pidgin English. Cocoliche survived only as renewed by fresh immigrants from Italy, its potential second-generation speakers being instead speakers of Spanish. Whinnom made clear that the circumstances under which a pidgin can emerge must be quite specialized and stressed the process not only of simplification, but also of stabilization of a discrete form of speech not mutually intelligible with the languages from which it derives.

Whinnom suggested characteristics also stressed by William Stewart as essential to effective pidginization: a multilingual situation; separation from the domain of use of languages of wider communication; marginality of the speakers among whom the pidgin arises, such that they are not corrected by, or integrated among, the users of established linguistic norms. Apparently, there must also be sufficient difference among the languages involved, so that interference of one set of linguistic habits with imperfectly acquired others has a marked effect. (In an original comparison of biological and linguistic theory, Whinnom discussed primary and secondary hybridization in a revealing way, and specified the formation of pidgins as "tertiary" hybridization.)

This discussion raised most of the major issues of the conference: the characteristics distinctive of these languages; what the characteristics imply about users of the languages; the linguistic and social prerequisites of the processes involved; theories as to the origin of known pidgins and creoles. 
Samarin reported on statistical studies of characteristics of pidgins and other forms of speech. Charles Ferguson noted that societies have varieties of speech that they themselves regard as simpler than others, and as suited for use with babies and foreigners. Their conventions must be studied as possibly shaping the outcome of pidginization. For example, absence of copula (forms of "to be" in English) is generally regarded, both by linguists and native speakers, as simpler than its presence. Ferguson proposed a series of relevant hypotheses. Their testing would help establish universal principles of simplicity as between forms of speech, and shed light on universals of language.

It was observed that the reduction of overt structure in pidgins may be accompanied by greater use of other modes of communication (intonation, gesture, facial expression); that greater cognitive effort may be involved in communicating with the restricted lexical and grammatical means of a pidgin; that there may be compensating complexities (as in length of sentences); and that the essential reduction of machinery special to particular languages could be seen as laying bare a substratum common to all.

John Reinecke, whose Yale dissertation thirty years ago was the first systematic American study of pidgin languages, described the Pidgin French spoken in Vietnam (Tay Boi), now vanishing with the withdrawal of the French. It is a classic case, with pronunciation essentially Vietnamese or French, according to the speaker, vocabulary from French, morphology simplified in the direction of Vietnamese, copula almost never used, and verbal means often eked out by gestures and intonation. Charles Frake analyzed the Zamboangueno dialect of Philippine Creole Spanish, whose history poses a number of problems for usual assumptions as to the nature and direction of lexical influence of one language on another. Of particular interest was the semantic structure associated with words of Philippine origin. Spanish vs. Philippine origin of words is not correlated with differences in the provenience of objects denoted (foreign vs. indigenous), but with the "unmarked" vs. "marked" in the sense of Joseph Greenberg's general theory. Philippine-derived words are, in contrast with those of Spanish origin, markers of the smaller, nearer, younger, female, plural, or worse of a pair. Where forms are differentiated by style, the Spanish term marks formality (politeness toward addressee), and the Philippine is the unmarked conversational form. This indicated to the conference a quite unexpected and original possibility of linking the analysis of creolization to the study of language universals. 


\section{Common origin}

A principal reason for the growth of attention to pidgins and creoles has been the hypothesis, developed only in the last decade, that most or all of them may have a common historical origin. The hypothesis is far from established, but it has already brought students of pidgin and creole languages together in a common field, where previously the study of one such language had been largely cut off from the study of others.

Some support for the hypothesis has appeared in a study by Morris Goodman that points to a common origin for all French-based creoles. Ian Hancock is advancing a similar thesis for English-based creoles. The general thesis is that there was an early Portuguese-based pidgin, rapidly stabilized, and readily relexified. From this standpoint, Chinese Pidgin English, for example, would not have arisen from confrontation of English and Chinese, but through adaptation of a pre-existing pidgin by speakers of Chinese. Frederic Cassidy discussed the linking of a pidgin element in Jamaican vocabulary to such a source. Such analysis of origins entails greater complexity of argument than can be summarized here, but clearly it is inseparable from social history, from specification of the location and movement of peoples at specific times, and from comparative analysis of the types of social situation in which communication occurred. Mervyn Alleyne challenges the Portuguese hypothesis, so far as Caribbean creoles are concerned, on just such grounds. He rejects, as do other creolists, the picture, derived in part from Leonard Bloomfield, of Europeans in each separate situation speaking baby talk or the like to inferiors, who in good faith adopt such talk while introducing features of their own language; and he accepts a common general origin for Caribbean creoles on the west coast of Africa; but he insists that the situation must be seen from the standpoint of Africans, learning one or another European language, and reinterpreting it in terms of patterns common to West African languages, leading to a syncretism in language like that well known in culture. Rather than a rapid crystallization of pidgins, Alleyne sees persistence of a continuum of variation from the most to the least standard (English, French), with the eventual outcome depending on the development of the total acculturation situation. Where the European linguistic model was withdrawn (as English was withdrawn from Surinam when Dutch was introduced), the creole end of the continuum is set off as a separate new language in a simple bilingual situation. Where the European model remains, as in Jamaica, the creole portion of the continuum moves steadily toward the standard, so that those who envisage an earlier dichotomy between 
the creole and standard language speak of the present situation as a postcreole continuum and predict the disappearance through absorption of the distinction.

Crosscutting this issue of the social process is the question of linguistic classification. Some would classify Haitian Creole as a dialect of French, Jamaican Creole as a dialect of English, etc., depending upon the European language from which the bulk of the vocabulary and, apparently, of morphological detail derives. Perhaps such classification is in part an effort to confer prestige upon the languages. Others point to the common grammatical patterns of Caribbean creoles whose lexical stocks are from diverse European languages, as evidence for their descent from a common pidgin ancestor, variously relexified, and as an indication that they are truly "new" languages, not properly to be classified or interpreted in terms of the usual methods of historical and comparative linguistics. In support of this view is the fact that basic vocabulary (the common core of meanings for body parts, natural objects, and the like found in all languages) tends to change at about the same rate in all languages, except pidgins (New Guinea Pidgin English) where the rate of change is wildly accelerated. From either point of view the different rates of change in basic vocabulary of pidgins and creoles challenge prevailing theory and recent procedures.

In a detailed study of Marathi and other Indo-Aryan languages of India, Franklin Southworth suggested that pidginization and creolization may have intervened in the history of indigenous Dravidian languages. John Gumperz provided evidence of almost total convergence in all but vocabulary forms between two contemporary Indian languages, one Dravidian (Kannada), one Indo-Aryan (a dialect of Marathi). Morris Goodman presented the problem of Mbugu, a language in Tanzania, whose grammatical structure pointed to Bantu origins, and whose basic vocabulary apparently did not. While inconclusive, these studies directed attention to the fact that if prior pidginization and creolization could have intervened widely in the past history of languages, many accepted classifications and subgroupings of languages would be of questionable validity. The great desideratum would be to establish linguistic, or social, criteria for the occurrence of the processes. Much more linguistic and social analysis is needed for this purpose. The results might considerably change usual approaches to linguistic prehistory and linguistic change.

\section{Present social roles}

Much of the interest of the conference, especially given the Caribbean setting, was in the status and consequences of creoles in contemporary societies. Jan 
Voorhoeve and Christian Eersel analyzed the situation in Surinam (former Dutch Guiana). A prestige variety of Sranan Tongo ("Church Creole") was developed by missionaries, and Voorhoeve's translation of the Bible into the nonprestigious Sranan vernacular is still under debate and cannot be used. Eersel analyzed choice between use of Dutch and Sranan Tongo in political affairs, personal relations between sexes and persons of different status, parents and children, etc. Sranan is becoming standardized and a vehicle of poetry. One comparison of interest is that to speak Dutch with standard grammar and vocabulary is good, but to speak it with a standard pronunciation is to put on airs. To speak standard Sranan with a standard Dutch ("bakara”) pronunciation, conversely, does confer prestige.

David DeCamp, Beryl Bailey, and Robert Le Page directed attention to problems of describing the actual state of affairs in a complex multilingual situation, wherein any given speaker (as in Jamaica) has command of not one norm, but a set of norms spanning part of a continuum. All introduced novel methodological devices for coping with such situations. DeCamp proposed a seven-point linguistic spectrum for Jamaica, and discussed ways of incorporating the multiplicity of varieties defined in the spectrum within a single set of rules of the sort used in transformational generative grammar. He argued that the limitation of a given speaker to some part of the continuum could find a place within a single grammar of the whole, and called for study of the factors that govern the actual switching of speakers within the span at their commandfactors whose operation is as yet unknown. Bailey established creole and standard as two ideal types, introducing the number of rules required to go from both types to a given text as a measure for categorizing it as one or the other. Le Page argued for starting with the individual speaker as the basis from which regularities and relationships must be built up. Comments on the papers raised many questions which descriptive linguistics has only begun to answer.

Dennis Craig raised the question of the cognitive consequences of use of a creole language (a point that Whinnom had also discussed), and reported studies of the effects of teaching of standard English in schools. There was considerable discussion of the interplay between features of language, education, attitudes, and social structure in Caribbean communities and others, such as Hawaii, and of the future of the creole speakers in them. 


\section{Overview}

In his concluding statement Sidney Mintz asked why present-day creoles are so largely concentrated in the Caribbean, and in the French and English (rather than Spanish) parts of it. He answered in terms of preconditions for creolization, giving a succinct demographic and historical analysis of a massively imported population caught up in quasi-urbanizing plantation life. Henry Hoenigswald spoke of the historical linguist as having two main interests in these languages: in their histories (genesis, change, disappearance), and in the relations of the phenomena of pidginization and creolization, and those of social change in general. In synthesizing many aspects of the discussion, he concentrated on the possible destructive consequences (noted above) of study of creoles and pidgins on notions of change, descent, family tree, and classification; and recommended clarification of the traditional concepts. Attention to classic cases in Indo-European showed the critical role of basic vocabulary in permitting a decision as to historical affiliation. There may be no sharp differentiation between pidginization and ordinary change in some sort of continuous space. Allen Grimshaw vigorously reviewed the development of comparative sociology, its relations with linguistics, and their areas of common interest. William Labov discussed types of linguists with respect to their methods and criteria for accepting results. Mentioning the near despair of some linguists in their efforts to write grammatical rules, he outlined several strategies for combining social and linguistic analysis to obtain convincing results.

Several memoranda indicating a variety of research needs had been circulated in advance of the conference. If a single result can be said to have emerged from the conference, it is somewhat ambiguous: retrospectively, considerable satisfaction in seeing the study of pidginization and creolization change from the marginal work of a few pioneers to a central object of research and theory; prospectively, a sense of urgency concerning the great amount of research needed to resolve the many problems brought into focus. There are still too few adequate descriptions of too few of the world's pidgin and creole situations; too few linguists able to approach the historical origins of these languages with a knowledge of their putative African sources; too few linguists able to study the use and consequences of these languages in a manner informed by social science. Some of the Caribbean scholars urged particularly that the relation of these languages to questions of national identity and literature be given concentrated attention at some future conference. It is likely that the next decade will see as great a transformation of our knowledge in all these respects as has the last. 
Items Editor's note: The author is Professor of Anthropology, University of Pennsylvania. As a member of the Council's Committee on Sociolinguistics, he was responsible, in collaboration with Gertrud Buscher, Lecturer in French at the University of the West Indies, for organizing the conference on which he reports here. The conference was made possible by a grant to the Council from the National Science Foundation, and funds allocated by the University of the West Indies.

Article note: This archival document has been reproduced the way it was initially published, with no further editing nor formatting of the bibliography. 